\title{
Comparing Health Impairments in Special Health Care Needs Children with and without Diabetes
}

\author{
Maureen K. Johnson", Florence Uruakpa \\ Department of Applied Health Sciences, Indiana State University, Terre Haute, 47809, Indiana, United States \\ *Corresponding Author: Maureen.Johnson@indstate.edu
}

Copyright $@ 2014$ Horizon Research Publishing All rights reserved.

\begin{abstract}
Health impairments in special health care needs (SHCN) children with diabetes were compared with those of SHCN children without diabetes. Data from the 2009/2010 National Survey of Children with Special Health Care Needs (NS-CSHCN) were analyzed. Demographic and health impairment variables were measured in terms of their association with ever being diagnosed with diabetes by a medical professional. Demographic variables included sex, ethnicity/race, and age group. Health impairment variables included difficulties with: swallowing/digesion/metabolism; coordination/movement; difficulties using hands or fingers; vision; hearing; breathing; and circulation. Multivariate logistic regression analysis and adjusted odds ratios (OR) were used to determine associations. The variables of sex, age group, swallowing/digestive/metabolic impairments, vision difficulties, and circulation impairments were significantly associated with ever having been diagnosed with diabetes. Findings from the current study suggest that SHCN children with diabetes have specific health impairments beyond those of other SHCN children without diabetes.
\end{abstract}

Keywords Special Health Care Needs, Diabetes, Health Impairments, Disabilities, Children

\section{Introduction}

Diabetes mellitus is a group of metabolic diseases which may cause increased blood sugar due to the inability of the pancreas to produce enough insulin (as in Type 1 diabetes)[1] or the cells' inability to secrete insulin or respond to the insulin that is produced (as in Type 2 diabetes).[2] Common symptoms of the condition include increased thirst and hunger, frequent urination, and possible changes in vision (in a more advanced state).[3,4] Adults 65 years of age and older are seven times more likely to have Type 2 diabetes than adults between 20 and 44 years of age.[5] While age is an established risk factor for Type 2 diabetes[5], US minority populations such as Hispanic Americans[5,6] and non-Hispanic African Americans[5,7] also have higher prevalence of diabetes than their Caucasian counterparts.

In 2011, approximately 8 percent of the US population had diabetes.[8] This translates to 26 million children and adults nationwide.[8] Of this number, 19 million people are diagnosed, 7 million people are undiagnosed, and 79 million people have pre-diabetes.[8] Diabetes is the seventh leading cause of death in the United States.[9]The 2011 age-adjusted death rate was 21.5 per 100,000 , which was a 3.4 percent increase from the 2010 age-adjusted death rate.[9]

Healthy People 2020 (HP 2020) addresses the need to prevent health complications associated with diabetes as well as diabetes itself.[10] Such complications include digestive disorders[11], coordination and movement difficulties[12-1 3], difficulty using one's hands or fingers[14-15],visual impairments[16-17], hearing impairments[18-20], respirator y impairments[21-22],cardiovascular and circulatory diseas es[23-26], neurological disorders[27], and kidney disease.[28-29] The potentially debilitating nature of complications associated with diabetes may decrease the quality of life as well as the life expectancy for individuals with diabetes.[30-31].

Diabetes has begun to emerge as a public health concern for another segment of the American population: children and adolescents under 18 years of age. In 2000, the CDC and the National Institutes for Health initiated the SEARCH for Diabetes in Youth study; one of several goals of SEARCH is to determine and prevent health impairments associated with diabetes among children and adolescents.[32] Between the years 2002 and 2005, 15,600 youth were diagnosed with Type 1 diabetes each year; during this same time period, 3,600 youth were diagnosed with Type 2 diabetes.[8] American youth may have

While diabetes has been recognized in the United States and around the world as a public health concern and a disability among adults, it is also identified as a special health care need among the population of children and youth under 18 years of age. The Maternal and Child Health Bureau's Division of Services for Children with Special Health Care Needs defines children with special health care needs (SHCN) as, "those who have or who are at increased risk for a chronic physical, developmental, behavioral, or emotional condition and who require health services of a 
type or amount beyond that required by children generally [33(p. 138)]." Under Section 504 of the Rehabilitation Act, children with diabetes are considered to have a disability or SHCN.[34]Children with diabeteshave an impairment of the endocrine system which may compromise their health as well as their academic progress; thus public schools are legally required to allow children with diabetes to check their blood sugar as well as eat when necessary.[35]

Diabetes has been legally established as a disability or SHCN [34], and previous studies have suggested children and adolescents with Type 1 diabetes have specific health impairments not experienced by their peers without diabetes $[11,36]$. However, there are very limited numbers of studies comparing health impairments between SHCN children and youth with diabetes with those of children and youth who do not have the disease. Such studies must be explored so that the specific health needs of children with diabetes may be distinguished from those children and youth who have SHCN's other than diabetes; otherwise, children and youth with diabetes may not receive necessary medical care in a timely manner, which could potentially compromise their health.[37]

\section{Objectives}

While diabetes has been identified as a special health care need, it is also necessary to differentiate specific health impairments from those of children with other special health care needs so that children with diabetes may be given medical attention to prevent and control specific health impairments associated with diabetes. Therefore, the purpose of the current study is to compare health impairments existing in SHCN children with diabetes with those present in SHCN children without diabetes.

\section{Materials and Methods}

The current study analyzed data collected through the 2009/2010 National Survey of Children with Special Health Care Needs (NS-CSHCN).[38] The 2009/2010 NS-SHCN was conducted as a part of the Child and Adolescent Health Initiative.[38] Data were collected with State and Local Area Integrated Survey (SLAITS), which was developed by the National Center for Health Statistics (NCHS).[39] SLAITS uses a random digit dial method and is used to collect health information at specific local and state levels as well as at the national level.[39]

For NS-CSHCN data collection, interviewers randomly dialed 196,159 households throughout the United States.[40] Among these households, 371,617 children were screened for special health care needs (SHCN).[40] If none of the children in the household were determined to have an SHCN, the interview was concluded. If a household contained more than one child with an SHCN, the subject of the NS-SHCN survey was randomly selected by the interviewer.[40] All interviews regarding the SHCN child in the households were conducted with the parent or legal guardian of the child.[40] Therefore, 40,242 children were the subjects of the complete NS-SHCN survey. Information concerning the informed consent process of the 2009/2010 NS-CSHCN may be accessed

athttp://www.cdc.gov/nchs/data/slaits/NS_CSHCN_Questio nnaire_09_10.pdf.[41]

\subsection{Variables}

All variables included in the current study were analyzed as categorical variables. For the analysis, the dependent variable was whether or not a health care provider has ever told the parent his or her child had diabetes. The demographic independent variables consisted of the sex, race/ethnicity, and age group of the SHCN children. The health impairment independent variables included swallowing, digestive, or metabolic difficulties; chronic pain including headaches; difficulty with coordination or moving around; difficulty using hands or fingers; difficulty with vision even when wearing glasses or contact lenses; difficulty hearing even with a hearing aid or another device; difficulty with breathing; and difficulty with blood circulation.

\subsection{Analysis}

Frequencies and percentages were used to summarize counts and proportions of SHCN children who had ever been diagnosed with diabetes. Frequencies and percentages were categorized by the demographic variables of sex (male or female); race/ethnicity (Hispanic; White, non-Hispanic; Black, non-Hispanic; and Other); and age group ( 0 to 5 years; 6 to 11 years; and 12 to 17 years). The option "Other" for the race/ethnicity variable was designated for SHCN children (e.g., Asian, Native American) who were not identified as Hispanic, White, or Black.

For analyzing the association of demographic and health complication variables with diabetes status, multivariate logistic regression analyses were used. The demographic variables were categorized as they were for descriptive statistics. For the each of the health variables, parents/guardians were able to respond with "a lot of difficulty", "a little difficulty", "no difficulty", "don't know", or "refused".[39] For the dependent variable of the SHCN child ever being diagnosed by healthcare provider as having diabetes, parents/guardians were able to respond with "yes", "no", "don't know", or "refused".[41,42] For the multiple logistic regression analyses, the dependent variables were entered as binary variables with only "yes" or "no" responses; observations with missing responses as well of "don't know" or "refused" were not included in the logistic regression analysis. In addition to descriptive statistics and multivariate logistic analyses, adjusted odds ratios (OR) were also calculated to determine the likelihood of ever being diagnosed with diabetes by specific groups within each 
variable.

A complex sampling technique was used in the collection of NS-SHCN data.[42] Therefore, the authors of the current study used SAS 9.2 statistical analysis software due to its ability to take into account the variance estimation resulting from the complex sampling procedure.

\section{Results}

\subsection{Health Impairments and Having Been Diagnosed with Diabetes}

Among the 40,242 of American children identified with special health care needs, there were 21,139 males and 16,033 females with 70 responses missing (Table 1).Of these participants, 4,479 were Hispanic, 27,989 were White, non-Hispanic, 4,010 were Black, and 3,764 were identified as "Other". In terms of the age distribution, 7,294 children were between the ages of 2 and 5; 15,834 were between 6 and 11 ; and 17,114 were between the ages of 12 and 17 .

A greater percentage of girls $(2.62 \%)$ than boys $(1.92 \%)$ were reported to have ever been diagnosed with diabetes. For the variable of race/ethnicity, White children had the greatest proportion $(2.29 \%)$ diagnosed with diabetes, followed closely by Hispanic and non-Hispanic, Black children (both 2.17\%), and children classified as "Other" $(1.62 \%)$ who had ever been diagnosed with diabetes. Finally, children of the oldest age group, 12 to 17 years, had a higher proportion $(3.12 \%)$ ever diagnosed with diabetes than either the 6 to 11 year olds $(1.83 \%)$ or the 0 to 5 years olds $(0.86 \%)$.

In terms of demographic independent variables, girls were more likely $(\mathrm{OR}=1.28, \mathrm{P}<0.05)$ to have been diagnosed with diabetes than males (Table 2). Furthermore, children between the ages of 6 and 11 were almost three times more likely $(\mathrm{P}<0.0001)$ than children between 0 and 5 years to ever have diabetes, whereas children between 12 and 17 were almost five times more likely $(\mathrm{P}<0.0001)$ to have ever been diagnosed with diabetes than children in the youngest age group. However, there were no statistically significant differences among racial/ethnic groups in terms of ever being diagnosed with diabetes.

Table 1. Demographic Factors of Special Health Care Needs Children Ever and Never Diagnosed with Diabetes

\begin{tabular}{|c|c|c|c|}
\hline & $\begin{array}{c}\text { Ever } \\
\text { Diagnosed } \\
\text { with } \\
\text { Diabetes } \\
(\%) \\
\end{array}$ & $\begin{array}{c}\text { Never } \\
\text { Diagnosed } \\
\text { with } \\
\text { Diabetes } \\
(\%) \\
\end{array}$ & Total \\
\hline \multicolumn{4}{|l|}{ Gender } \\
\hline Male & $\begin{array}{c}464 \\
(1.92 \%) \\
\end{array}$ & $\begin{array}{c}23657 \\
(98.08 \%) \\
\end{array}$ & 24121 \\
\hline Female & $\begin{array}{c}419 \\
(2.62 \%) \\
\end{array}$ & $\begin{array}{c}15602 \\
(97.38 \%) \\
\end{array}$ & 16021 \\
\hline Total & 883 & 39259 & $40142^{\mathrm{a}}$ \\
\hline \multicolumn{4}{|l|}{ Race/ethnicity } \\
\hline Hispanic & $\begin{array}{c}97 \\
(2.17 \%)\end{array}$ & $\begin{array}{c}4377 \\
(97.83 \%)\end{array}$ & 4474 \\
\hline $\begin{array}{c}\text { White, non- } \\
\text { Hispanic }\end{array}$ & $\begin{array}{c}641 \\
(2.29 \%) \\
\end{array}$ & $\begin{array}{c}27331 \\
(97.71 \%) \\
\end{array}$ & 27972 \\
\hline $\begin{array}{c}\text { Black, non- } \\
\text { Hispanic }\end{array}$ & $\begin{array}{c}87 \\
(2.17 \%) \\
\end{array}$ & $\begin{array}{c}3922 \\
(97.83 \%) \\
\end{array}$ & 4009 \\
\hline Other & $\begin{array}{c}61 \\
(1.62 \%) \\
\end{array}$ & $\begin{array}{c}3696 \\
(98.38 \%) \\
\end{array}$ & 3757 \\
\hline Total & & & $40212^{b}$ \\
\hline \multicolumn{4}{|l|}{ Age of CSHSCN } \\
\hline $0-5$ Years & $\begin{array}{c}63 \\
(.86 \%) \\
\end{array}$ & $\begin{array}{c}7227 \\
(99.14 \%) \\
\end{array}$ & 7290 \\
\hline 6-11 Years & $\begin{array}{c}290 \\
(1.83 \%)\end{array}$ & $\begin{array}{c}15532 \\
(98.17 \%)\end{array}$ & 15822 \\
\hline 12-17 Years & $\begin{array}{c}533 \\
(3.12 \%) \\
\end{array}$ & $\begin{array}{c}16567 \\
(96.88 \%) \\
\end{array}$ & 17100 \\
\hline Total & 886 & 39326 & $40212^{c}$ \\
\hline
\end{tabular}

a Note: 100 observations missing due to responses of "don't know" or "refused" when responding to question concerning SHCN child's gender. b Note: 30 observations missing due to responses of "don't know" or "refused" when responding to question concerning SHCN child's race/ethnicity.

c Note: 30 observations missing due to responses of "don't know" or "refused" when responding to question concerning SHCN child's age. 
Table 2. Multiple Logistic Regression Analysis and Adjusted Odds Ratios for Ever Being Diagnosed with Diabetes among Children with Special HealthCare Needs $(N=39,581)^{\mathrm{b}}$

\begin{tabular}{|c|c|c|c|c|}
\hline Parameter & $\begin{array}{c}\text { Estimate } \\
(\beta)\end{array}$ & S.E. & P Value & OR $(95 \% \mathrm{CI})$ \\
\hline \multicolumn{5}{|l|}{ Sex } \\
\hline Male & & & & 1.000 (Reference) \\
\hline Female & $0.2444 *$ & 0.1210 & 0.0435 & $1.277(1.007-1.619)$ \\
\hline \multicolumn{5}{|l|}{ Race } \\
\hline Hispanic & & & & 1.000 (Reference) \\
\hline White, non-Hispanic & -0.1300 & 0.1970 & 0.5093 & $0.878(0.597-1.292)$ \\
\hline Black, non-Hispanic & 0.0560 & 0.2456 & 0.8195 & $1.058(0.654-1.711)$ \\
\hline Other & -0.2492 & 0.3024 & 0.4099 & $0.779(0.431-1.410)$ \\
\hline \multicolumn{5}{|l|}{ Age Group } \\
\hline 0 to 5 & & & & 1.000 (Reference) \\
\hline 6 to 11 & $1.0568 * *$ & 0.2226 & $<.0001$ & $2.877(1.860-4.451)$ \\
\hline 12 to 17 & $1.5512^{* *}$ & 0.2237 & $<.0001$ & $4.717(3.043-7.313)$ \\
\hline \multicolumn{5}{|l|}{$\begin{array}{c}\text { Swallowing/ } \\
\text { digestive/ } \\
\text { metabolic difficulties }\end{array}$} \\
\hline A lot of difficulty & & & & 1.000 (Reference) \\
\hline A little difficulty & -0.3821 & 0.2640 & 0.1477 & $0.682(0.407-1.145)$ \\
\hline No difficulty & $-1.3416^{* *}$ & 0.2593 & $<.0001$ & $0.269(0.162-0.446)$ \\
\hline \multicolumn{5}{|l|}{$\begin{array}{c}\text { Coordination/ } \\
\text { movement difficulties }\end{array}$} \\
\hline A lot of difficulty & & & & 1.000 (Reference) \\
\hline A little difficulty & 0.6883 & 0.4669 & 0.1405 & $1.990(0.797-4.970)$ \\
\hline No difficulty & $1.6519^{* *}$ & 0.4459 & .0002 & $5.217(2.177-12.502)$ \\
\hline \multicolumn{5}{|l|}{$\begin{array}{c}\text { Difficulties using hands } \\
\text { or fingers }\end{array}$} \\
\hline A lot of difficulty & & & & 1.000 (Reference) \\
\hline A little difficulty & -0.2830 & 0.3474 & 0.4153 & $0.753(0.381-1.489)$ \\
\hline No difficulty & -0.1753 & 0.3256 & 0.5903 & $0.839(0.443-1.589)$ \\
\hline \multicolumn{5}{|l|}{ Difficulty with vision } \\
\hline A lot of difficulty & & & & 1.000 (Reference) \\
\hline A little difficulty & 0.0190 & 0.3077 & 0.9508 & $1.019(0.558-1.863)$ \\
\hline No difficulty & $-0.6331 *$ & 0.2671 & 0.0178 & $0.513(0.298-0.885)$ \\
\hline \multicolumn{5}{|l|}{ Difficulty with hearing } \\
\hline A lot of difficulty & & & & 1.000 (Reference) \\
\hline A little difficulty & 0.6781 & 0.5701 & 0.2342 & $1.970(0.645-6.022)$ \\
\hline No difficulty & 0.7859 & 0.5079 & 0.1217 & $2.194(0.811-5.937)$ \\
\hline \multicolumn{5}{|l|}{ Difficulty with breathing } \\
\hline A lot of difficulty & & & & 1.000 (Reference) \\
\hline A little difficulty & -0.3326 & 0.2510 & 0.1850 & $0.717(0.438-1.173)$ \\
\hline No difficulty & $0.8062 * *$ & 0.2027 & $<.0001$ & $2.239(1.505-3.332)$ \\
\hline \multicolumn{5}{|l|}{ Difficulty with circulation } \\
\hline A lot of difficulty & & & & 1.000 (Reference) \\
\hline A little difficulty & -0.1018 & 0.4668 & 0.8274 & $0.903(0.362-2.255)$ \\
\hline No difficulty & $-1.2211^{* *}$ & 0.4620 & 0.0082 & $0.295(0.119-0.729)$ \\
\hline
\end{tabular}

a661 observations were deleted due to missing values for response or explanatory variables.

*significant at the 0.05 level.

** significant at the 0.01 level 
For the health complication variables, children with no difficulty with digestion and swallowing were approximately 3.7 times less likely $(P<0.0001)$ to have been diagnosed with diabetes than children who had a great deal of difficulty with digestive impairments. Also, children having no difficulty with visual impairments and with blood circulation were approximately two $(P<0.05)$ and three times $(P<0.01)$ less likely, respectively, to have ever been professionally diagnosed with diabetes. However, children with no coordination or movement difficulties were more than five times more likely $\mathrm{P}<0.001)$ to have ever been diagnosed with diabetes than children having a lot of difficulties in this area. Furthermore, children with no respiratory difficulties were more than twice as likely $(P<0.0001)$ to ever have been diagnosed with diabetes than children reported to have a great deal of respiratory impairments. For the complications of difficulties using hands or fingers, chronic pain, or hearing, no statistically significant adjusted odds ratios were calculated for having ever been diagnosed with diabetes (Table 2).

\subsection{Limitations}

In the consideration of the findings of the current study, several limitations must be noted. One such limitation is that while the focus of the current study was to compare health complications in SHCN children with and without diabetes, other special health care needs may have confounded the relationship between the explanatory variables and response variable. For instance, SHCN children with no difficulty hearing were more likely (though not significantly so) to have diabetes than children who had a great deal of difficulty hearing. It is possible there were SHCN children in the study who had hearing impairments attributed to disorders other than diabetes.

A second limitation of the current study was that the SHCN children were not differentiated as Type 1 or Type 2 diabetes. Type 1 diabetes tends to occur during childhood or adolescence, and it results in the inability of the pancreas to produce insulin.[1] Type 2 diabetes commonly has an initial onset during adulthood and results in the body's inability to properly use insulin.[2] However, because of the increase in the proportion of American children and adolescents who are overweight or obese, it is possible that at least some of the SHCN children in the current study had Type 2 diabetes. Different physiological mechanisms are caused by Type 1 diabetes (inability of the pancreas to produce insulin)[1] than by Type 2 diabetes (inability of the body to effectively use the produced insulin)[2]; therefore, it is possible that there may be a difference in susceptibility to specific complications between the two types of diabetes.

A third limitation of the current study was that the responses to the survey were based on reports from parents and guardians. Thus, the provided responses were subject to recall bias as well as to parents'/guardians' perceptions and knowledge of the medical conditions about which they were interviewed. For instance, a child who had four instances of difficulty seeing throughout the year could be interpreted as "a little difficulty" by some parents/guardians and "a lot of difficulty" by other parents/guardians.

\section{Discussion and Conclusions}

As with the population of adults, increasing age seemed to influence whether or not a child in the current study had ever been diagnosed with diabetes.[43] Adolescents between the ages of 12 and 17 were more likely to be diagnosed with diabetes than children in the younger age groups. However, adolescents are generally more capable of communicating their symptoms with parents and medical professionals. Furthermore, the increase in the obesity rates among adolescents may further contribute to an increased risk in diabetes. This association is supported by the National Health and Nutrition Examination Survey (NHANES) findings between the years 1999 to 2006, which reported an increased prevalence of diabetes with an increase in weight among adults in the United States.[44] About 50\% of diabetic adults are considered obese, indicating that weight loss is an important intervention tool in an effort to reduce the impact of diabetes.[44] Consequently, obtaining and maintaining a healthy weight is essential for the short-and long-term prevention of diabetes in adolescents as well.

While not statistically significant, Black, non-Hispanic SHCN children were more likely to have been diagnosed with diabetes. This finding is consistent with those of current literature and national reports[4, 7-8], indicating the need to invest additional resources in monitoring diabetes among children belonging to racial and ethnic minority populations.

Many of the results of the current study are consistent with those conducted with adults in terms of digestive/swallowing/metabolic[11], visual [16-17] and circulatory[23-26] impairments associated with diabetes. Although such impairments tend to be associated with increasing age, the results of the current study suggest the need to monitor and control these conditions at an early age among children with diabetes as well.

Several of the findings of the current study were inconsistent with those of previous studies; these were the findings with impairments in coordination/movement and difficulties with respiration. While previous studies suggested coordination[12-13] and breathing[21-22] complications were associated with diabetes, findings from the current study indicated that SHCN children who did not have difficulties with these two functions were more likely to have been diagnosed with diabetes than those children who had a great deal of difficulty. However, these findings may be somewhat encouraging, as both coordination and respiratory functions must be intact in order for children to engage in physical activity as well as routine daily tasks (e.g., self-care).

Previous studies have suggested children and adults with diabetes may experience health impairments not experienced (or not experienced to the same extent) by healthy peers 
$[11,36]$, thus confirming diabetes as a SHCN according to the definition provided by the Maternal and Child Health Bureau.[33] However, the findings of the current study suggest that children with diabetes may experience specific impairments (e.g., vision, digestion, and circulation impairments) to a greater extent than children with other SHCN's. This lends additional support to diabetes' classification as an SHCN and speaks to the need to avoid using a generic approach in meeting the needs of SHCN children.

Parents and guardians must monitor their SHCN children with diabetes for complications such as vision impairments, digestion/metabolism, and circulation. Medical providers and other professionals involved with the care of such children must also be vigilant, as these complications may compromise both quantity and quality of life. A lack of attendance to physical needs during childhood may also result in chronic health conditions throughout adulthood.[45]

Public health officials at local, state, and national levels must also take measures to prevent complications associated with diabetes among children. The Healthy People 2020 initiative addresses the prevention and control of such health impairments related to diabetes and includes objectives such as "increase the proportion of adults with diabetes who have at least an annual foot exam" [46, HP 2020 Objective D-9] and "increase the proportion of adults with diabetes who have an annual dilated eye exam".[46, HP 2020 Objective D-10] However, these specific objectives seem to target adults rather than children and youth under the age of 18 . While HP 2020 includes objectives relevant to diabetes prevention among children and adolescents under 18 (e.g., increased physical activity and weight control), no objectives currently address the need to monitor and control possible diabetes-related complications (e.g., visual impairment and circulation) among children and adolescents. Findings from the current study confirm that the complications of visual impairment, digestive/metabolic difficulties, and circulatory impairments are as prevalent in diabetes as with other special health care needs. Public health initiatives and policies must enforce the prevention and control of such complications among children with diabetes throughout the nation and the world.

\section{REFERENCES}

[1] Khardori, R, Type 1 diabetes mellitus, Medscape, Online available from http://emedicine.medscape.com/article/117739-overview.

[2] Khardori, R, Type 2 diabetes mellitus, Medscape, Online available from http://emedicine.medscape.com/article/11785 3-overview.

[3] World Health Organization, Media Centre, Diabetes, Online available fromhttp://www.who.int/mediacentre/factsheets/fs 312/en/index.html.
[4] C. Taber. Taber's Cyclopedic Medical Dictionary, F.A. Davis Company, United States of America, 1985.

[5] Center for Disease Control and Prevention (2012). Diabetes Report Card, 2012. National Center for Chronic Disease Prevention and Health Promotion: Division of Diabetes Translation., Online available fromhttp://www.cdc.gov/diabe tes/pubs/pdf/DiabetesReportCard.pdf.

[6] S. Black, L. Ray, K. Markides. The prevalence of health burden of self-reported diabetes in older Mexican Americans: findings from the Hispanic Established Populations for Epidemiologic Studies of the Elderly, American Journal of Public Health [serial online], Vol. 89, No. 4, 546-552., 1999. Available from: CINAHL, Ipswich, MA. Accessed July 22, 2013.

[7] C. Ching-Yu, D. Reich, C. Haiman, et al. African ancestry and its correlation to type 2 diabetes in African Americans: a genetic admixture analysis in three U.S. population cohorts, Plos ONE [serial online], Vol. 7, No. 3, 1-9, 2012. Available from: Academic Search Complete, Ipswich, MA. Accessed July 23, 2013.

[8] Center for Disease Control and Prevention (2011). National Diabetes Fact Sheet: National estimates and general information on diabetes and prediabetes in the United States, available online from http://www.cdc.gov/diabetes/pubs/pdf/ ndfs_2011.pdf.

[9] D. Hoyert, J. Xu. Deaths: Preliminary data for 2011. National vital statistics reports. Vol. 61, No. 6, 2012. Hyattsville, MD: National Center for Health Statistics, Available online from http://www.cdc.gov/nchs/data/nvsr/nvsr61/nvsr61_06.pdf. Accessed July 26, 2013.

[10] Healthy People 2020. Topics and objectives: Diabetes overview. Updated April 10, 2013, Available online from http://www.healthypeople.gov/2020/topicsobjectives2020/ov erview.aspx?topicid=8. Accessed July 26, 2013.

[11] A. Horvath, P. Dziechciarz, K. Dzygalo K, S. Dybkowska. Prevalence of functional gastrointestinal pain-related disorders in children and adolescents with type 1 diabetes. Gastroenterological Polska [serial online], Vol. 19, No. 3, 111-113, 2012. Available from: Academic Search Complete, Ipswich, MA. Accessed July 22, 2013.

[12] T. Roman de Mettelinge, D. Cambier, P. Calders P, et al. Understanding the relationship between type 2 diabetes mellitus and falls in older adults: a prospective cohort study. Plos ONE [serial online], Vol. 8, No.6, 1-5, 2013. Available from: Academic Search Complete, Ipswich, MA. Accessed July 22, 2013.

[13] R. Gadsby, P. Barker, A. Sindair. People living with diabetes resident in nursing homes-assessing levels of disability and nursing needs. Diabetic Medicine [serial online]. Vol. 28, No.7, 778-780, 2011. Available from: Academic Search Complete, Ipswich, MA. Accessed July 22, 2013.

[14] P. Bade-White, J. Obrzut. The neurocognitive effects of type 1 diabetes mellitus in children and young adults with and without hypoglycemia. Journal of Developmental and Physical Disabilities [serial online]. Vol. 21, No. 5, 425-440, 2009. Available from: Academic Search Complete, Ipswich, MA. Accessed July 22, 2013.

[15] J. Lewko, B. Polityńska, e. Krajewska-Kułak E, et al. Median nerve conduction impairment in patients with diabetes and its 
impact on patients' perception of health condition: a quantitative study. Diabetology and Metabolic Syndrome [serial online];Vol. 5, No.1, 1-12, 2013. Available from: Academic Search Complete, Ipswich, MA. Accessed July 31, 2013.

[16] N. de Fine Olivarius, V. Siersma, G. Almind, N. Nielsen. Prevalence and progression of visual impairment in patients newly diagnosed with clinical type 2 diabetes: a 6-year follow up study. BMC Public Health[serial online], Vol. 11, No. 80, 1-13, 2011. Available from: Academic Search Complete, Ipswich, MA. Accessed June 25, 2013.

[17] A. Ryskulova, K. Turczyn, D. Makuc, et al. Self-reported age-related eye diseases and visual impairment in the United States: results of the 2002 National Health Interview Survey. American Journal of Public Health[serial online], Vol. 98, No. 3, 454-461, 2008. Available from: Academic Search Complete, Ipswich, MA. Accessed July 23, 2013.

[18] K. Bainbridge, H. Hoffman, C. Cowie. Risk factors for hearing impairment among U.S. adults with diabetes: National Health and Nutrition Examination Survey 1999-2004. Diabetes Care[serial online], Vol. 34, No. 7, 1540-1545, 2011. Available from: Academic Search Complete, Ipswich, MA. Accessed June 25, 2013.

[19] P. Mitchell, B. Gopinath, C. McMahon CM, et al. Relationship of Type 2 diabetes to the prevalence, incidence and progression of age-related hearing loss. Diabetic Medicine[serial online], Vol. 26, No. 5, 483-488, 2009. Available from: Academic Search Complete, Ipswich, MA. Accessed June 25, 2013.

[20] K. Pemmaiah, D. Srinivas. Hearing loss in diabetes mellitus. International Journal of Collaborative Research on Internal Medicine and Public Health[serial online]. Vol. 3, No. 10, 725-731, 2011.Available from: Academic Search Complete, Ipswich, MA. Accessed June 25, 2013.

[21] O. Klein, R. Kalhan, M. Williams, et al. Lung spirometry parameters and diffusion capacity are decreased in patients with Type 2 diabetes. Diabetic Medicine[serial online].Vol. 29, No. 2,212-219, 2012. Available from: Academic Search Complete, Ipswich, MA. Accessed June 25, 2013.

[22] P. Fsadni, C. Fsadni, S. Fava, S. Montefort . Correlation of worldwide incidence of type 1 diabetes (DiaMond) with prevalence of asthma and atopic eczema (ISAAC). Clinical Respiratory Journal[serial online], Vol. 6, No.1, 18-25, 2012. Available from: Academic Search Complete, Ipswich, MA. Accessed July 23, 2013.

[23] C. Boyd, B. Leff, C. Weiss, et al. Informing Clinical Practice Guideline Development and Implementation: Prevalence of coexisting conditions among adults with coronary heart disease, Journal of the American Geriatric Society [serial online], Vol. 59, No. 5, 797-805, 2011. Available from: Academic Search Complete, Ipswich, MA. Accessed July 23, 2013.

[24] A. Huebschmann, W. Kohrt, J. Regensteiner. Exercise attenuates the premature cardiovascular aging effects of type 2 diabetes mellitus. Vascular Medicine [serial online], Vol. 16, No. 5, 378-390, 2011.Available from: Academic Search Complete, Ipswich, MA. Accessed July 22, 2013.

[25] W. Davis, M. Knuiman , T. Davis T. An Australian cardiovascular risk equation for type 2 diabetes: the Fremantle Diabetes Study. Internal Medicine Journal [serial online], Vol. 40, No. 4, 286-292, 2010. Available from: Academic Search Complete, Ipswich, MA. Accessed July 22, 2013.

[26] N. Turanjanin, M. Jovicevic M, K. Bozic, M. Zarkov. Frequency of ischemic stroke subtypes in relation to risk factors for ischemic stroke. Healthmed [serial online], Vol. 6, No. 10, 3463-3468, 2012. Available from: Academic Search Complete, Ipswich, MA. Accessed July 22, 2013.

[27] M. Rizzi , M. Barrella, G. Kotzalidis, M. Bevilacqua M. Periodic limbic movement disorder during sleep as diabetes-related syndrome? A polysomnographic study. ISRN Endocrinology [serial online], January 2011;1-5. Available from: Academic Search Complete, Ipswich, MA. Accessed July 24, 2013.

[28] S. Barquera, I. Campos-Nonato, C. Aguilar-Salinas, et al J. Diabetes in Mexico: cost and management of diabetes and its complications and challenges for health policy. Globalization and Health [serial online], Vol. 9, No. 3, 2013. Available from: MEDLINE, Ipswich, MA. Accessed July 24, 2013.

[29] J. Zacharias, T. Young, N. Riediger, et al. Prevalence, risk factors and awareness of albuminuria on a Canadian First Nation: a community-based screening study. BMC Public Health [serial online], Vol. 12, No. 1, 290-297, 2012. Available from: Academic Search Complete, Ipswich, MA. Accessed July 24, 2013.

[30] L. Jelsness-Jørgensen, L. Ribu, T. Bernklev, B. Moum. Measuring health-related quality of life in non-complicated diabetes patients may be an effective parameter to assess patients at risk of a more serious disease course: a cross-sectional study of two diabetes outpatient groups. Journal of Clinical Nursing [serial online], Vol. 20, No. 9/10, 1255-1263, 2011. Available from: Academic Search Complete, Ipswich, MA. Accessed July 22, 2013.

[31] L. Loukine, C. Waters, B. Choi, J. Ellison. Impact of diabetes mellitus on life expectancy and health-adjusted life expectancy in Canada. Population Health Metrics [serial online], Vol. 10, No. 1, 7-16, 2012. Available from: Academic Search Complete, Ipswich, MA. Accessed July 24, 2013.

[32] Wake Forest Baptist Medical Center. SEARCH for Diabetes in Youth. About SEARCH. 2013. Accessed July 24, 2013. Available online from https://www.searchfordiabetes.org/pu blic/dspAbout.cfm.

[33] McPherson, M., Arango, P., Fox, H., Lauver, C., McManus, M., Perrin, J. M., \& ... Strickland, B. (1998). A new definition of children with special health care needs. Pediatrics, 102(1), 137-140.

[34] U.S. Department of Health and Human Services (2006). Fact Sheet: Your Rights Under Section 504 of the Rehabilitation Act. Available online from http://www2.ed.gov/policy/rights /reg/ocr/edlite-34cfr104.html. Accessed October 26, 2013.

[35] American Diabetes Association (n.d.). Your School and Your Rights: Protecting Children with Diabetes in Schools. Available fromhttp://main.diabetes.org/dorg/PDFs/Advocac y/your-school-your-rights.pdf. Accessed October 25, 2013.

[36] A.M. Patino-Fernandez, A. Delamater, E. Brooks Applegate, E. Brady, M. Eidson, R. Nemery, L. Gonzalez-Mendoza, S. Richton. Neurocognitive functioning in pre-school age children with type 1 diabetes mellitus. Pediatric Diabetes, Vol. 11, No. 6, 424-430, 2010. 
[37] P. Kofoed, J. Thomsen, J. Ammentorp. An unplanned delay between control visits influences the metabolic status in children with diabetes. ActaPaediatrica[serial online], Vol. 99, No. 5, 774-777, 2010. Available from: Academic Search Complete, Ipswich, MA. Accessed July 22, 2013.

[38] 2009/10 National Survey of Children with Special Health Care Needs. Fast facts about the survey. Maternal and Child Health Bureau in collaboration with the National Center for Health Statistics, Data Resource Center for Child and Adolescent Health, Child andAdolescent Health Measurement Initiative. Accessed July 24, 2013. Available online

fromhttp://www.childhealthdata.org/docs/default-document-1 ibrary/ns-cshen-fast-facts-2009.pdf. Accessed July 24, 2013.

[39] Centers for Disease Prevention. About the State and Local Area Integrated Telephone Survey. Available online from http://www.cdc.gov/nchs/slaits/about_slaits.htm. Accessed July 24, 2013.

[40] 2009/10 National Survey of Children with Special Health Care Needs. Sampling and survey administration process. Maternal and Child Health Bureau in collaboration with the National Center for Health Statistics. Data Resource Center for Child and Adolescent Health, Child and Adolescent Health Measurement Initiative. Available online from http:/www.childhealthdata.org/docs/default-document-librar y/2009-nscshen-survey-sampling-administration.pdf.Accesse d June 25, 2013.

[41] 2009/10 National Survey of Children with Special Health Care Needs Questionnaire Version December 14, 2011. Maternal and Child Health Bureau in collaboration with the National Center for Health Statistics. Sponsored by the Health Resources and Services Administration, Maternal and Child Health Bureau Conducted by the National Center for Health Statistics, Centers for Disease Control and Prevention.
Available online from http://www.cdc.gov/nchs/slaits/cshcn. htm. Accessed June 25, 2013.

[42] 2009/10 National Survey of Children with Special Health Care Needs. Maternal and Child Health Bureau in collaboration with the National Center for Health Statistics. [SAS] 2009/10 NS-CSHCN Indicator Data Set prepared by the Data Resource Center for Child and Adolescent Health, Child and Adolescent Health Measurement Initiative. Available online from www.childhealthdata.org.

[43] V. Wagner, E. Muller-Godeffroy, S. von Sengbusch, et al. Age, metabolic control and type of insulin regime influences health-related quality of life in children and adolescents with type 1 diabetes mellitus. European Journal of Pediatrics, [serial online], Vol. 164, No. 8, 491-496, 2005. Available from: Academic Search Complete, Ipswich, MA. Accessed June 25, 2013.

[44] N. Nguyen, X. Nguyen, J. Lane, P. Wang. Relationship between obesity and diabetes in a US adult population: findings from the National Health and Nutrition Examination Survey, 1999-2006. Obesity Surgery [serial online], Vol. 21, No. 3, 351-355, 2011. Available from: http://link.springer.co m/article/10.1007/s11695-010-0335-4/fulltext.html. Accessed August 17, 2013.

[45] C. SpatzWidom, S. Czaja, T. Bentley, M. Johnson. A prospective investigation of physical health outcomes in abused and neglected children: new findings from a 30-year follow up. American Journal of Public Health[serial online]. Vol. 102, No. 6, 1135-1144, 2012. Available from: CINAHL, Ipswich, MA. Accessed June 25, 2013.

[46] Healthy People 2020. Topics and objectives: Diabetes: Objectives. Available online from http://www.healthypeople.gov/2020/topicsobjectives2020/ob jectiveslist.aspx?topicId=. Accessed July 26, 2013. 